\title{
El realismo estético del cine documental en la tesis de Pier Paolo Pasolini
}

\section{The Aesthetic Realism of Documentary Cinema in Pier Paolo Pasolini's Thesis}

\author{
Rubén Dittus \\ Universidad Católica de la Santísima Concepción, Chile \\ rdittus@ucsc.cl
}

\section{Resumen:}

La tesis cinematográfica de Pier Paolo Pasolini se sustenta en la idea de que la realidad no es natural, sino cultural. El cine nos lo revela, y al hacerlo tomamos conciencia de que no se actúa sobre la realidad sino dentro de ella, como si fuera un continuo sistema de signos en el que formamos parte. La revisión de la teoría semiótica del director y ensayista italiano en Estados Unidos lo ha retornado al centro del debate en los estudios fílmicos de Occidente. El principal efecto es la re-actualización de los escritos semióticos de Charles Sanders Peirce. Este artículo postula que las bases realistas del cine documental se acercan al falso naturalismo del que habla Pasolini, tras homologar gran parte de los procesos perceptivos que nutren la mente del espectador.

Palabras clave: cine documental, Pasolini, semiótica, realismo estético, Peirce.

\begin{abstract}
:
Pier Paolo Pasolini's cinematographic thesis is based on the idea that reality is not natural, but cultural. Thus cinema reveals it, making us aware of the fact that we do not act upon reality but live inside of it, as if reality was a continuous system of signs which we form part of. The revision, in the United States, of the semiotic theory of the Italian director and essayist has returned to the eye of the western movie debates, mainly due to the new readings of the works by Charles Sanders Peirce. The following article claims that the realistic bases of documentary cinema come close to the false naturalism refered by Pasolini by mixing great part of the perceptive processes that nourish the spectator minds.
\end{abstract}

Keywords: Documental Cinema, Pasolini, Semiotic, Aesthetic Realism, Peirce. 


\section{La imagen fílmica como transparencia}

La teoría fímica tradicional sugiere que el denominado "cine de no ficción" solo puede ser concebido dentro de su inscripción referencial. Se trata de una reflexión convertida en paradigma y que poco dice sobre la eficacia pragmática del género, más preocupada de la semejanza proyectada en la recepción que del natural peso del referente en el registro audiovisual. En ese contexto, la tesis cinematográfica de Pier Paolo Pasolini, para quien la realidad no es natural sino cultural, sigue siendo revolucionaria. El director italiano, hace más de treinta años, proponía una teoría de la imagen fílmica basada en el supuesto de que los objetos representados en la pantalla tienen cierta relación analógica con su contrapartida real, fuera del filme. En la actualidad, dicho naturalismo vive un interesante proceso de revisión, superando la visualidad analógica y el estatus de una imagen fílmica que desechó el doble vínculo de la lingüisticidad de la realidad y del cine.

La estética de Pasolini cobra revitalización hoy en día tras el constatar los protocolos exigidos cada vez que se quiere escribir algo sensato sobre la imagen, más allá de los análisis importados desde la lingüística o la literatura. En este punto es habitual observar los alcances metodológicos que vinculan el mapa con el territorio, como si se pasara por alto la artificialidad de las imágenes. El resultado es conocido: la imagen se torna invisible en dichos análisis, como si solo actuara como un cristal transparente al que no hay que prestarle atención. Usando la metáfora del cartógrafo, se trata de un mapa -la imagendel cual no existe territorio. La reflexión parte de una constatación fenomenológica: si no hay más realidad que las imágenes que se forman en nuestra psique, el acceso directo a ese territorio se hace imposible. Somos meros cartógrafos que usamos múltiples mapas de algo llamado realidad que no puede ser observada al margen de dichos instrumentos de observación. Sin embargo, a menudo naturalizamos dicha percepción haciendo una equivalencia entre nuestros estados de percepción y los estados de realidad. En palabras de Josep María Català: "Ver es una acción tan natural que tendemos a considerar que carece de significado en sí misma, porque suponemos que el conocimiento genuino tampoco explica nada: se limita a ser y por lo tanto se adquiere mediante un acto de comunicación directa con la realidad, cuyo ejemplo más emblemático es precisamente la visión" (Català, La imagen compleja 17). El resultado en la praxis es que la imagen habla como si no dijera nada.

¿A qué se debe esta insistencia -tan occidental- de asimilar a la imagen a un mero espejo? Vemos la visibilidad representada, no la imagen en sí. No hay separación entre discurso y figura, por lo que es habitual encontrarnos con la idea de espejo o calco, suponiendo que el contacto genuino con el mundo evita detenerse en la copia. Son las dificultades de acceder a la observación en un segundo orden las que parecen llevarnos a una derrota anticipada. Hemos interiorizado el código que sustenta nuestra percepción, y lo hacemos reificando el más universal de todos, el universo de las imágenes visuales. Para Català ( La violación de la mirada 22), esa internalización es tan relevante que aplicamos a menudo esa estructura codificada a otros códigos visuales que no están organizados del 
mismo modo. La pintura, la fotografía o el cine se adaptan a esos procesos perceptivos. La propia psicología no ha resuelto este tema de forma categórica. Si para el conductismo existe una equivalencia entre imagen y pensamiento verbalizado, no es mucho más lo que se puede esperar. De hecho, la importancia de las imágenes mentales sigue teniendo resistencia en importantes áreas del conocimiento que ven en el psicoanálisis solo una corriente desprestigiada.

Al no percibir el régimen visual autónomo de las imágenes, la seguimos, pero amparados en lo que ella representa. Pensamos en el modelo, en el supuesto territorio, apartándonos de cualquier probable inmersión simbólica e imaginaria. Cuando se aplica esta naturalización visual, no es extraño que se ignore a la imagen en la mayoría de las corrientes que impulsaron los estudios cinematográficos. Se trata de un proceso de naturalización que se debe a su propia complejidad y que alimenta una serie de críticas a una semiótica incapaz de superar metodologías más lingüísticas que han transformado el análisis de la imagen en un apéndice de otras lecturas. Català señala:

La semiótica había llegado con la imagen a un callejón sin salida. La interpretación lingüística parecía incapaz de dar cuenta del fenómeno de la imagen, puesto que había acabado por equiparar todos los fenómenos comunicativos, anulando cualquier especificidad: no importaba que se hablase de literatura o pintura, de cine o música: todo era lenguaje (La violación de la mirada 17).

En efecto, la primera semiótica del cine basa su reflexión en dicho plantamiento. Sin embargo, gracias a esa primera aproximación lingüística, es que el cine comienza a ser pensado como algo distinto al referente. Recordemos los escritos de Christian Metz en esta materia que lo llevan a concluir que el cine no es una lengua, pero sí un lenguaje con códigos particulares. De hecho, cuando Metz aborda la denominada "especificidad cinematográfica", lo hace señalando que solo puede darse en dos niveles: en un discurso fílmico y en un discurso a base de imágenes. La especificidad del cine es la presencia de un lenguaje que quiere hacerse arte en el seno de un arte que quiere hacerse lenguaje, explica Metz. Dice:

La película tal como la conocemos, no es una mezcla inestable: lo que sucede es que sus elementos no son incompatibles. $Y$ si no lo son, es porque ninguno de ellos es una lengua. No se pueden emplear dos lenguas al mismo tiempo: quien se dirige a mí en inglés no lo hace en alemán [...] Los lenguajes, por el contrario, toleran mejor este tipo de superposiciones, al menos dentro de ciertos límites: quien se dirige a mí por medio de lenguaje verbal (inglés o alemán) puede al mismo tiempo gesticular (Metz 95).

En el contexto histórico y disciplinar en que se producen, los escritos de Metz suponen una evidente influencia de la lingüística de Saussure -y profundizada por los trabajos de Andrè Martinet- cuando afirmaba que la imagen no conoce nada homólogo a la segunda articulación de las lenguas naturales, es decir, a la articulación de los fonemas. Y que aquella tampoco se puede homologar con los morfemas -unidades de primera articulación que actúen como marcas gramaticales (de número, género, etc.)-, ni a los 
lexemas o palabras. La multiplicidad de códigos con las que opera el filme será el primer antecedente que reconozca a una semiótica del cine, ocupada tanto de los significantes visuales como sonoros. Metz lo hace convirtiendo el filme en texto, pero un texto que nada tiene que ver con la lengua de Saussure. He aquí una primera diferencia identitaria para la naciente semiótica del cine de los años setenta. En la tesis metziana, las materias de expresión fímica son los puentes que permiten al cine extenderse y apoderarse de toda una serie de territorios ajenos, pero dotados de una identidad propia. Así, el filme roba lenguajes ya consolidados para mezclarlos, superponerlos y articularlos visualmente.

La analogía de Metz no es antojadiza. Teorías de quienes fueron sus contemporáneos o estudios anteriores han abordado esa relación entre el cine y el lenguaje. Sergei Eisenstein, por ejemplo, asimilaba el lenguaje cinematográfico a una especie de lenguaje interior, parecido a un pensamiento primitivo que estimulaba el reconocimiento de las obras de arte constituídas por asociaciones visuales o sonoras, incluido el cine. A partir de la relación de ideas simples se podía constituir algo parecido a un lenguaje, pero de menor complejidad. Serán otros estudios -como los de Rudolf Arnheim- los que reconocerán la figura del pensamiento visual o sensorial, distinto al lingüístico, pero que no son considerados por la naciente semiótica del cine de fines de los años setenta.

Es a partir de esta convicción epistemológica que recogemos la crítica que se hace a la clásica lectura cinematográfica. El caso del documental es aún más sensible a estos reparos por las semejanzas que guarda con la fotografía. El uso que se ha hecho de la imagen como pretexto para abordar el contenido de un filme, sin ningún viraje desde o hacia la percepción, se explica por las dificultades que tiene cualquier disciplina para no contaminarse de los paradigmas dominantes o sustrarse de la invisibilidad de una imagen que actúa como un efectivo dispositivo visual. Son los efectos que supone no considerar a la imagen por sí misma. Frente a esta nueva fenomenología del documental, las fronteras entre naturaleza y cultura que delimitó Eco a fines de lo sesenta parecen acotadas y, desde luego, son insuficientes para la empresa semiótica en la actualidad. Los avances en teoría de la imagen y las exigencias derivadas de los nuevos formatos audiovisuales han actualizado la discusión respecto al clásico umbral.

\section{El cine-lengua de Pasolini}

En dicha actualización se valoran autores olvidados como Pasolini, quien -paradójicamente- no indica en su teoría que las imágenes sean transparentes, sino que enfatiza el carácter lingüístico de las mismas para explicar que la realidad se ha convertido en cine. Defiende la idea de un cine-lengua, compuesta por la articulación de unidades mayores, como el encuadre, lo cual transformaría el referente en un conjunto de unidades que hacen posible la existencia de aquellos cinemas equivalentes. El resultado: la existencia de un código similar al lenguaje verbal, pero constituido por imágenes-símbolos parecidos -no en estricta equivalencia- a las palabras. La re-lectura del escritor y cineasta italiano lo ubica 
en una especie de nueva fenomenología de lo visual-cinematográfico, que parte de una constatación inicial: el destinatario del producto cinematográfico está habituado también a leer visualmente la realidad. Esto repercute necesariamente en el carácter de lengua que otorga al cine. La comunicación visiva que está en su base estructural es extremadamente burda y animal, escribe Pasolini (Empirismo herético 235), razón por la que el instrumento lingüístico sobre el que se implanta el cine es de tipo irracional. Ejemplo de ello es la cualidad onírica del cine -rasgo en que concuerda Metz-y su carácter concreto u objetual, pues lo que observa el espectador en la pantalla no es motivo de discusión. Al igual que fuera del mundo cinematográfico, el ser humano se manifiesta a través de imágenes significantes, anteriores a cualquier forma de organización verbal, y que denomina im-signos. Se trata de modos pre-gramaticales e incluso pre-morfológicos, dice Pasolini (Empirismo herético 235), muy propio de la estructura de los sueños y de los mecanismos que emplea la memoria.

Esta naturaleza análoga, no lingüística, pero de tipo significante, que se atribuye al cine y a los im-signos del mundo real imaginario confirman lo planteado por Metz: no existe un diccionario de las imágenes. Para Pasolini, sin embargo, este hecho no impide hablar de la existencia de una lengua cinematográfica. Escribe:

El autor cinematográfico no posee un diccionario sino una posibilidad infinita: no toma sus signos (im-signos) del estuche, del bagaje, sino del caos, donde no son más que meras posibilidades o sombras de comunicación mecánica y onírica. Por lo tanto, la operación del autor cinematográfico no es una, sino doble [...] debe tomar del caos el im-signo, hacerlo factible, y presuponerlo como sistematizado en un diccionario de los im-signos significativos (mímica, ambiente, sueño, memoria) [...] y debe realizar después la operación del escritor, agregar a tal im-signo puramente morfológico la cualidad expresiva individual (Pasolini, Empirismo herético 236-7).

Así, para Pasolini, el principal rasgo del cine es que se trata de una convención estética antes que gramatical, algo que no lo aleja del patrimonio de lo común. Lo que vemos en la pantalla son objetos reales que están incorporados en nuestro universo de registros visuales y que se estimulan con el cinematógrafo. Ello le permite a Pasolini afirmar que no existen los objetos en bruto, ya que todos son suficientemente significantes por naturaleza como para convertirse en signos simbólicos los cuales, antes de ser incorporados de forma concreta y no abstracta por el autor cinematográfico, tienen una historia pregramatical más larga e intensa que en el propio cine. Se trata de una convencionalidad objetiva que se logra a partir de la creación de un vocabulario estético propio -y no lingüístico- que el cineasta elabora en cada filme, todo ello a pesar de que sea imposible una lengua cinematográfica institucional.

Lo anterior confirmaría para Pasolini la existencia de una estructura estética pero a nivel inconsciente, allí donde aún no es posible una lengua en los términos como a esta se le conoce. En efecto, los dardos del autor apuntan a la insistencia en abordar la estructura lingüística desde la lógica saussuriana, como si fuera imposible ampliar y modificar la noción de lengua. La idea de la realidad como un cine "in natura" va precisamente en esa dirección, donde el primer y principal lenguaje de los hombres es la acción misma en 
cuanto relación recíproca con los demás y con la realidad física. Es decir, toda la vida, en el conjunto de sus acciones, es un cine natural y viviente, y lingüísticamente es el equivalente a la lengua oral en su momento natural o pregramatical. De hecho, Pasolini nunca habló en un principio de una lengua normativa, tal como insistentemente se le atribuye, ni menos de una gramática fímica. Es a partir de un artículo de Christian Metz en 1964 -Le cinéma: langue ou langage?- donde el italiano reconsidera muchos de los postulados de su tesis. En respuesta a Metz, Pasolini presenta un esquema gramatical que se enfrenta a los dichos de Metz con quien reconoce tener un desacuerdo, pero "no insuperable". En el texto La lengua escrita de la realidad (1966) Pasolini llama a estar listos para aceptar la escandalosa existencia de una lengua sin doble articulación. Situación que, por lo demás, no se aplica al cine, ya que según el autor, una forma de segunda articulación se da también en el cine. Agrega:

No es verdad que la unidad mínima del cine sea la imagen, cuando por imagen se entienda aquella ojeada que es el encuadre o, en suma, lo que se ve con los ojos a través del objetivo. Todos -tanto Metz como yo- siempre hemos creido esto. En cambio: la unidad mínima de la lengua cinematográfica son los diversos objetos reales que componen un encuadre (Empirismo herético 278).

Como se observa, la revolucionaria propuesta alude directamente a los objetos concretos del mundo real precinematográfico. Su incorporación como unidades mínimas de esta "nueva lengua audiovisual", la cinelengua, se sostiene en la idea de que al excluir o incluir a uno u otro objeto real del encuadre, se cambia al encuadre en cuanto significante. Una idea que, en palabras de Pasolini, es escandalosa en términos saussurianos. Por analogía, todos esos objetos, formas o actos de la realidad permanentes dentro de la imagen cinematográfica, son denominados cinemas. Pero a diferencia de los fonemas de la lengua de Saussure, los cinemas son infinitos. Por su parte, los monemas del cine son, para Pasolini, los encuadres, cuyas posibilidades de composición son igualmente variadas, tantas como la realidad natural y la imaginación lo permitan. De hecho, la intraducibilidad del cinema al que alude Pasolini tiene una gran similitud con el sentido obtuso de Barthes. En ambas nociones, se dificulta cualquier intento de traducir el lenguaje fílmico a otro verbalizado, a pesar de que Pasolini reconoce en el primero un continuo visual o cadena de imágenes que se perciben linealmente, a pesar de que el encuadre aparece por completo "de una sola vez" ante la vista del espectador, ya que -como en toda lengua- hay una curva de sucesión que se condice con cualquier forma de percepción. Ello equivale a decir que dicha lengua es paralela a la realidad que expresa, o que la cadena gramatical de los significantes es paralela a la serie de significados.

En otras palabras, el cine, al reproducir la realidad, nos revela que la realidad misma es un lenguaje, invitándonos a tomar conciencia de ello. En efecto, si todo es lenguaje, las cosas, los gestos, las acciones y la realidad bruta en general es un sistema coherente de signos que se hace visible a través del cine. Este reconocimiento ha llevado a algunos biógrafos e investigadores a plantear que tanto la práctica como teoría cinematográfica de Pasolini se ubica más bien como parte del análisis de los procesos de producción del 
cine y de la sociedad; un análisis en el que se enfatiza no el cine en cuanto medio de expresión sino en los actos y discursos que lo componen (Mariniello 101). El resultado es una semiología de la realidad que se nutre del cine para explicar la semiosis. Se invierte el ejercicio, y con él, se ponen los cimientos para lo que Pasolini alguna vez escribió como meta intelectual:

Desde hace tiempo tengo la ambición de escribir una filosofía del cine consistente en la inversión del nominalismo: no nomina sunt res sino res sunt nomina (...) En suma, la realidad (espiada por el cine) es un conjunto cuya escritura es la estructura de un lenguaje (Pasolini, Empirismo herético 250).

Dicha ambición filosófica está llena de contradicciones, pues por un lado recoge la idea central de Charles Peirce, la de concebir la lengua como uno de los muchos sistemas de signos posibles que constituyen la realidad, pero por otro lado, también incluye los postulados de Saussure. De hecho, la similitud que existe entre los conceptos que propone el italiano para su cinelengua está llena de alusiones a la lingüística saussureana, como la misma noción de lengua y sus posibilidades de articulación. Otras semejanzas son las observadas en sus reflexiones en torno a la lengua oral, la que a juicio de Pasolini "es, por principio, la relación del hombre con la naturaleza, prehistórica e inconsciente" (Pasolini, Empirismo herético 70) y sus rasgos analógicos, que lo separan del signo escrito, que es artificial y arbitrario. Dicha relevancia en el pensamiento de Pasolini se observa en el centro de su teoría cinematográfica, pues la lengua oral es un concepto que sirve para describir la realidad y la relación entre cine y realidad: el cine es la lengua escrita de la realidad. En otras palabras, la escritura nos revela la naturaleza cultural de la lengua oral, que se ubica en cada una de las acciones que desarrollamos. Entonces, la realidad no es el referente, pues no se da fuera de la acción, que incluye pensamiento y emociones, sino que es ella misma una lengua y la acción el primer lenguaje del hombre. Escribe Pasolini:

la acción humana en la realidad, en cuanto lenguaje primero y primigenio de los hombres. Por ejemplo, los vestigios lingüísticos del hombre prehistórico son modificaciones de la realidad debidas a las acciones de la necesidad: el hombre se ha expresado en tales acciones. Las transformaciones de las estructuras sociales, con sus consecuencias culturales, etc., son el lenguaje con el que se expresan los revolucionarios. Lenin, en cierto modo, ha dejado escrito un gran poema de acción (Pasolini, Empirismo herético 200).

Uno de los principales efectos de dicha constatación es el valor asignado al concepto de representación. Si el cine -en la terminología pasoliniana- no representa la realidad, es lógico, entonces, que la imagen analógica sea acusada de transparencia, tal como enfatiza Català. La diferencia que propone Pasolini, sin embargo, no debe ser vista como una carencia analítica respecto a los necesarios acercamientos que la semiótica tiene sobre la imagen, sino como un cambio de paradigma. Para Pasolini, el cine no es un medio por el cual alguien representa a través de imágenes, movimiento y sonido el mundo exterior. Lo que el cine hace es anular la realidad, dejándola como un mero referente sin valor sígnico alguno. La imagen es lo real. Y si es transparente es porque no habría que 
reconocer diferencia o interlocutor entre la realidad y la imagen. La ausencia de mimesis en el cine es lo central en la tesis de Pasolini, como si el modelo -la realidad en lenguaje natural- participara de la misma naturaleza de la imagen. De ello se deriva la idea de que la acción misma puede ser considerada el primero y el más importante de los lenguajes humanos, en cuanto relación de recíproca representación con los demás y con la realidad física. Es como si el objeto filmado se uniera a la creación artificiosa que produce el filme, en lugar de ser sustituido por otra cosa. El cinelengua, al expresar la realidad por medio de la realidad, crea una imagen que es idéntica a su modelo, que participa de su naturaleza y que es percibido como tal por el espectador. De ahí que haya postulado su ambicioso programa que ve al "cine como semiología de la realidad".

Siguiendo la misma línea, los efectos interpretativos cinematográficos son sugerentes; desafían a una semiótica acostumbrada a mirar al cine como un sistema de representación que se crea a partir de un referente. Si ya no se plantea la representación como la base fenomenológica del cine, es ahora la mediación entre un sujeto lingüístico y el mundo discursivo en el que actúa lo que orienta las estructuras perceptivas del espectador. El infinito proceso de interpretación que supone la semiosis peircena se actualiza en las ideas de Pasolini, ya que el sujeto, frente a la gran pantalla, regresa de nuevo a una realidad que no es natural sino que es lenguaje y que es objeto de múltiples lecturas y discursos. Se trata de un momento psíquico y dinámico en el que muchos lenguajes que tejen la realidad se nutren y transforman recíprocamente. Es la no naturalidad de tiempo, dice Pasolini, lo que da cuenta de la reproducción cinematográfica. Los momentos filmados y que luego son articulados a través del montaje falsifican la realidad, simulándola. Es en ese instante, donde se pone en evidencia todo el proceso de artificialidad que el cinelengua produce a partir de la realidad precinematográfica. En la síntesis fímica de cinco minutos donde se narra la vida de un hombre se produce el desajuste perceptivo. El cine nos hace conscientes de la falta de sentido de la realidad antes de la muerte, dice Pasolini, una continuidad fímica que es solo ilusoria, pues se aparta de la continuidad natural, y donde el tiempo es solo presente.

Este rasgo del cine pasoliniano es similar al que produce la escritura en nuestra lectura de la realidad. La escritura altera la lengua oral, pues acentúa su linealidad, transformando la acción en algo divisible y mensurable. Ello nos recuerda lo que escribe varios años después Marshall McLuhan sobre los efectos de la imprenta: la denominada "Galaxia Gutenberg”. Es el desarrollo de lo visual sobre lo acústico, la prevalencia de lo lineal por sobre lo simultáneo. La escritura facilita la separación del sujeto respecto al objeto. El pensamiento científico se nutre de dicha capacidad de objetivación. En el filme, tanto el tiempo como el espacio se convierten en elementos objetivables y manipulables. Así, el cine es a la lengua escrita lo que realidad es a la lengua oral: para Pasolini, el cine -a través de su continuum estilístico y narrativo- es la lengua escrita de la realidad, con los mismos efectos revolucionarios:

El cine, como lengua escrita de la realidad, tiene probablemente (y ello se verá mejor en los próximos años) la misma importancia revolucionaria que ha tenido la 
invención de la escritura. Esta última ha sido lo primero en revelar al hombre qué es la lengua oral. Ciertamente se trata del primer salto hacia adelante de la nueva conciencia cultural humana nacida de la invención del alfabeto; la conciencia de la lengua oral o, tout court, la conciencia de la lengua [...] Los mismos procedimientos revolucionarios que ha supuesto la lengua escrita respecto a la lengua hablada conllevará el cine respecto a la realidad (Pasolini, Empirismo herético 235).

Podríamos decir que es el efecto impostergable que se produce con cualquier sistema que traduzca el lenguaje de la realidad para llevarlo a otros códigos significantes. La realidad se altera, se reduce el caos, pero según una subjetividad ordenada cuya estética es similar, en el caso de Pasolini, a la de la poesía, pero que al mismo tiempo no es separable de la institución cine: su naturaleza como producto de la cultura de masas. "Revolución" y "poesía” parecen ser los dos elementos de un binomio que da cuenta de los alcances que tiene el cine como instrumento de expresión para los grandes públicos. El lenguaje poético articula toda la tesis de Pasolini, elevando al cine a un estatuto especial donde las infinitas variaciones de la realidad se hacen posible por medio de los atributos que ponga en pantalla el director, desde su particular visión de las cosas, pero no olvidando que es siempre un lenguaje que hace alusión a otro lenguaje, y en base a representaciones posibles, simuladas y naturalizadas. No se debe olvidar que para el director y poeta italiano la realidad es un sistema de signos, pero de gran complejidad, y la consciencia de que esta realidad es un lenguaje se debe precisamente al cine, cuya auténtica función es la de ser solo un intermediario, entre lo real y la escritura. Son las técnicas audiovisuales las que crean una lengua institucional cinematográfica donde ya no es posible separarla de la realidad.

La misión del cine como expresión de la "verdadera esencia del lenguaje de los actos que constituyen la base de la realidad" se observa en la obra cinematográfica de Pasolini. La importancia que otorgó a la presencia física de los personajes es un ejemplo de coherencia con su perspectiva teórica. Ángel Quintana repasa este rasgo en los filmes Acattone (1961) y /l Vangelo secondo Matteo (1964), donde, a su juicio, la vida primitiva de los campesinos y el rostro de los ragazzi di vita en los suburbios de la ciudad hablan por sí solos, como un lenguaje que se apoya solo en la naturaleza primaria de las cosas que formaban parte del universo del relato (Quintana 155). No existe una separación entre los objetos y el mundo, ni entre el cine y la realidad, apunta Quintana, refiriéndose a la obra pasoliniana. En la misma línea analítica, Silviestra Mariniello profundiza los alcances estéticos de las películas que forman parte de la Trilogía de Pasolini: /l Decameron (1971), I Racconti di Canterbury (1972) e /l fiore delle Mille e una Notte (1974): "El concepto de fisicidad del personaje, del lugar y del gesto se hace particularmente importante; el cine es explorado y entendido principalmente como el medium que puede transmitir tal fisicidad. De ahí la obsesiva insistencia en las localizaciones, las búsqueda incansable de rostros y cuerpos" (Mariniello 368). El materialismo de las imágenes en la Trilogía ha sido considerado, además, como una propuesta ideológica en la que Pasolini se subleva contra el poder burgués dominante, particularmente contra la filosofía del consumo y los valores 
que pregona la sociedad neocapitalista en la Italia de los años setenta. Esto explicaría la sobrevaloración que el cine pasoliniano otorga a lo corpóreo-erotizante, pues con ello el director italiano estaría exponiendo exageradamente la falta de realismo del discurso cotidiano de las sociedades occidentales que oculta la sexualidad bajo la sombra del juicio moral público, convirtiendo en tabú uno de los sistemas simbólicos más universales del ser humano. Al respecto, el análisis de Mariniello es enfático:

La sexualidad de la Trilogía está inscrita en la fisicidad de los personajes: ruidosos, alegres, gordos o delgados, barbudos, desdentados, despeinados, gruñones o sonrientes, bellos - pero de una belleza no habitual-, embrutecidos por la miseria o por el vino, tímidos o descarados pero, sobre todo, totalmente descuidados en lo que a su aspecto se refiere. Una provocación escandalosa en una sociedad preocupada principalmente por la apariencia (Mariniello 369-70).

Ese aspecto "no ideológico" (o ideológicamente subliminal) es el que Pasolini potencia en sus películas. La manifiestación de realismo es insuperable, pues se obtiene por connotación e inducción. La alegría de los personajes, la ausencia de una tensión psicológica, la rebelión atípica (los ancianos se rebelan, no así los jóvenes) o la ausencia de culpables en su Trilogía son aspectos estilísticos que potencian ese contradiscurso burgués. La presencia de actores "no profesionales" es otro rasgo de la personalidad de Pasolini como director, pues lo que buscaba en la pantalla era autenticidad, aunque ello le demandara mucho más trabajo, repitiendo tomas las veces que fuera necesario. Esto se observa especialmente en en rodaje de Salò o le centoventi giornate di Sodoma (1975), una de sus películas más emblemáticas (y censuradas), basada en la novela del Marqués de Sade Las 120 jornadas de Sodoma. El filme ha sido definido por la crítica como una puesta en escena del genocidio cultural provocado por la violencia del poder en sus más crudas manifestaciones históricas, y donde el ser humano ha sido reducido a un objeto de consumo, al igual que cualquier otro elemento de la sociedad capitalista. La sobreexposición de los cuerpos, su desnudez y la fragilidad de las víctimas frente a la tortura y la vejación son parte del relato que Pasolini utiliza como una metáfora para visibilizar el poder fascista, objeto de reprobación de una moral democrática y progresista, y dibujándolo como una aberración histórica. La alegoría presente en Salò pone de manifiesto las construcciones discursivas que tejen la historia de los hombres, y respecto de las cuales no sacamos lecciones adecuadas. Es tarea del cine, dirá Pasolini en múltiples entrevistas, recordar sobre la fluidez del futuro a partir de lo que ha quedado escrito en la realidad. Dice Pasolini:

El futuro es previsible, pero no la historia. Dicho de otro modo, los sociólogos pueden prever numerosas cosas: quizá las formas del hábitat, la cantidad de botones para pantalones que se fabricará en Alemania e incluso el número de nacimientos... Pero la fluidez histórica del futuro siempre se les escapará. No es expresable (Pasolini, Escritos corsarios 69). 


\section{El dilema semiótico: analogía o natura}

Como se observa, la naturalización del lenguaje de la realidad que Pasolini buscaba, no solo es nítida en su teoría, sino también en su polémica producción audiovisual. Es a través de sus películas donde el italiano hizo masiva su idea de estudiar los códigos culturales, por sobre el mero y superficial análisis de la imagen visual. Pero ¿por qué se clausuró tan drásticamente el debate en torno al cinelengua que propuso Pasolini? No cabe duda que su teoría causó malestar e incomodó a los representantes de la semiótica europea más ortodoxa. Su revolucionaria tesis no solo acaparó reflexiones académicas, sino que su particular estilo y énfasis ideológico terminó por darle la razón a sus detractores y, al menos durante un par de décadas, al más emblemático semiólogo italiano desde los años sesenta: Umberto Eco, considerado el responsable de enterrar las posibilidades de una iconicidad pura para el cine y para la imagen en general. En su clásico Apuntes para una semiología de las comunicaciones visuales (1967), Eco escribe sobre el itinerario reflexivo de la tesis pasoliniana y reafirma, en cambio, la idea de que existe una concurrencia contextual que dispone al espectador a ver las imágenes en la pantalla, donde todo es convención y cultura, incluso el proceder gestual que Pasolini atribuye a las acciones de la naturaleza. Para Eco, este tipo de comunicación no tiene nada que ver con la acción como gesto comunicante, tal como postula Pasolini, de la misma forma como Lévi-Strauss abordaba los utensilios de una comunidad como hechos de comunicación. Para Eco, ya existe una semiótica que se preocupa de estos elementos, y se llama cinésica:

Estas observaciones liquidarían también la idea de Pasolini de un cine como semiología de la realidad, y su convicción de que los signos elementales del lenguaje cinematográfico son los objetos reales reproducidos sobre la pantalla (convicción, ahora lo sabemos, de singular ingenuidad semiológica, y que contrasta con las más elementales finalidades de la semiología, que son las de reducir eventualmente los hechos naturales a fenómenos culturales, y no de reconducir los hechos de cultura a fenómenos naturales) (Eco, La estructura ausente 278).

La crítica de Eco se enfrenta a la intención de Pasolini de convertir a la semiótica del cine en solo un capítulo de la semiología general de la realidad, tras la tesis de que los diversos filmes, para ser comprendidos, no remiten al cine sino a la realidad misma. Es el reconocimiento de la realidad en el cine -la natura sin su representación- lo que no convence a Eco, sobre todo tras su intento de sentar las bases de una semiótica general que domine los umbrales que separan lo natural de lo cultural.

Pero hay otro dato. La equivalencia que Pasolini propone entre el código de la realidad y el código del cine cuestiona uno de los cimientos en los que se estaba levantando la semiótica de aquellos años, como disciplina autónoma de la lingüística. De hecho, una de las advertencias que señala Eco, para tener presente en una investigación semiológica, es que no todos los fenómenos significativos son explicables con las categorías de la lingüística. Es decir, la razón del fracaso de Pasolini se debe a los fundamentos de la semiótica y sus efectos en el análisis de la imagen visual. Allí se observa que hay un largo trayecto epismético que ubica a la imagen como un dispositivo textual y, como cada texto, 
actúa como un todo discursivo coherente por medio del cual se llevan a cabo estrategias de comunicación. Pero tiene algunas particularidades: la imagen no se representa de manera directa por medio de objetos, sino por medio de operaciones materiales, perceptivas y reglas gráficas y tecnológicas. Esto significa que la manera que la semiótica tradicional tiene de abordar a la imagen es reconociendo elementos diferenciales de su expresión, niveles sintagmáticos separables, niveles intertextuales que actúan como instrumentos funcionales y coherencias que se dan en el plano de su organización isotópica.

Todo esto ha permitido estudiar la imagen en el plano del contenido y no solo de la forma, pero siempre alejada de la equivalencia que propuso Pasolini. Es posible partir la observación de la estructura de la imagen desde una dimensión puramente presignificativa o plástica, pero cuando indagamos en lo que trata de significar, le otorgamos una función semiótica. Desde este lugar, la imagen no es signo o palabra, sino texto. Y el texto, como eje de una producción e interpretación comunicativa, es una "máquina semánticopragmática que pide ser actualizada en un proceso interpretativo, cuyas reglas de generación coinciden con las propias reglas de interpretación" (Eco, Lector in fábula 89). En la actualización interpretativa, Eco nos dice que la imagen no solo dice algo, sino que es un texto abierto que se ajusta a un "lector modelo", formado cognitivamente según su propia enciclopedia. En palabras nuestras, un espectador modelo que transforma la imagen en cantera de acontecimientos y mundos posibles y que le revelan al lector su propia imagen.

Ahora, si nos situamos solamente en el plano de la expresión, dejamos la imagen subvalorada como mera configuración iconográfica de objetos, lugares o personas. Con ello, abandonamos a la imagen como texto y la dejamos instalada solo como signo. Y si el plano del significado de una imagen se manifiesta a través de la expresión icónica, no cabe duda que el nivel de la expresión visual es tan artefacto como la lengua natural. He aquí el primer punto de desencuentro con la lingüística, antecesora saussureana de la semiología. Para aquella, la analogía no es considerada rasgo de una lengua. Es la ausencia de su doble articulación la que la deja fuera del campo disciplinar, dirían los lingüistas, razonamiento que es asumido por la semiótica de Eco y aplicado al análisis cinematográfico. Pero hay que ser justos. Contra el purismo icónico también se enfrentaron Barthes y Metz. De hecho, este último fue el principal detractor de la tesis cinematográfica de Pasolini. Fue Metz quien consignó la tesis de los grados de analogía en su artículo "Au-delà de l'analogie, l'image" (1970), proponiendo que en toda imagen hay siempre un mensaje que nada tiene de analógico. La misma analogía está ya codificada, escribe, y por lo tanto, culturalmente determinada. La tesis es clara: para Metz, toda imagen se utiliza y comprende en virtud de convenciones sociales que descansan en la existencia del lenguaje. Por su parte, Roland Barthes, menos drástico que Eco y Metz, defenderá su idea de que no existe una imagen inocente o puramente denotada. A pesar de ello, y del visible estructuralismo que lo cobija, su tesis respecto a la fotografía como un "mensaje sin código" lo ubica en una situación menos ortodoxa para la semiótica de esos años.

Para Eco, una semiótica del cine no puede ser solamente una teoría de la transcripción de la espontaneidad natural (idea que ya se apoya en la cinésica), sino que debe 
estudiar las posibilidades de su trascripción icónica, las modificaciones que se observan de los código preexistentes y la influencia de los respectivos sistemas de convenciones empleados (Eco, La estructura ausente 280). La respuesta de Pasolini no se hizo esperar y fue publicada en 1967 en su ensayo El código de los códigos. Allí aborda los argumentos a través de los cuales una semiología de las comunicaciones visivas puede constituirse en puente hacia la definición semiológica de otros sistemas culturales. Para Pasolini, la existencia imprecisa de los sinsignos (aquellos signos propios de la realidad física y material en la terminología de Peirce) son los que aprueban la total culturización de la realidad natural: “¿O quieres relegar estos sinsignos reales al limbo de la naturaleza no culturalizable?", le pregunta a Eco (Pasolini, Empirismo herético 379). Y agrega con sarcasmo:

En efecto, cada uno de nosotros y cada uno de los objetos y eventos de la realidad es signo icónico de sí mismo. No solo, además tú mismo has delineado una posible catalogación saussuriana del asunto, remontándote graciosamente a la cienciaficción: el doble del que hablas no sería otra cosa que la abstracción de la langue viviente deducida a partir de la presencia de la parole viviente constituida por la Reina Isabel en persona [...] Esto que acontece con respecto a las personas vivientes y conscientes como somos nosotros dos y a la Reina de Inglaterra, sucede también en el caso de las bestias, las cosas, los eventos: los sinsignos vivientes, los sema. También ellos son signos figurales de sí mismos en concreto, en su presencia física no intercambiable, sino violentamente singular; mientras son símbolos figurales de sí mismos en la langue constituida por generalizaciones, por clasificaciones, por géneros, por especies, por todo lo que, en suma, es general, público, etc. (Pasolini, Empirismo herético 381).

Es la auto-revelación lo que permite la codificación de ese algo o alguien para un sistema de signos convencionalizado. Sin ese código inicial llamado realidad, la Reina Isabel no podría siquiera ser fotografiada. Mientras tanto, sigue activo el debate sobre la responsabilidad de Eco en el supuesto inmovilismo semiótico en materia de percepción visual. Para los disidentes de la postura tradicional, la naturaleza icónica y el régimen de verdad que rodea a la imagen fotográfica constituye la prueba de que dicha percepción está altamente consensuada por los investigadores de la disciplina semiológica, pero no resuelve el problema de fondo. La noción de la imagen como algo que tiene un parecido con el objeto real ha significado, en la práctica, dilatar la formulación de una teoría que indague con éxito la transparencia de lenguajes como la fotografía y el género documental o, en su defecto, reactivar la tesis de Pasolini. El problema radica en la constitución de una traductibilidad de la imagen visual. Jean-Marie Schaeffer, por ejemplo, considera irrefutable la noción de dispositivo visual, lo que aplicado a la imagen fotográfica, supone desechar de plano la tesis de Eco. Schaeffer escribe:

Yo diría que los argumentos de Eco no demuestran lo que pretende demostrar, a saber, el carácter codificado de la relación analógica, por el tanto de la iconicidad fotográfica. Además, su concepción de la imagen fotográfica deja de lado la especificidad de esta imagen, ya que no toma en cuenta su dimensión indicial, y por eso 
mismo deja de lado el parentesco de génesis que existe la imagen y la percepción fisiológica, parentesco de génesis que desemboca en una analogía de las formas en imágenes con los esquemas perceptivos (Schaeffer 31-32).

El autor agrega que no se puede sostener la idea de una selección de rasgos de un objeto según un código de reconocimiento por convención cuando hay tan poca fidelidad entre la imagen y la percepción. La relación analógica - dice Schaeffer- está garantizada por el dispositivo óptico, cuya única finalidad es la producción de una imagen traducible en formas perceptivas. He ahí el denominado parentesco de génesis de la imagen fotográfica con la percepción fisiológica, ontología que la distingue como un signo no convencional o, en palabras de Barthes, como "un mensaje sin código" (Barthes 26).

\section{Los dos umbrales del cine documental}

Parece sensato, entonces, ubicar al cine documental como parte de una especificidad cinematográfica que se mueve entre dos umbrales: el lenguaje fílmico altamente codificado y la identificación referencial. Las imágenes del género, al igual que la fotografía, son percibidas como imágenes indiciales, ya que generan impresión y no significado, en la medida que solo reproduce signos instituidos. Pero, al mismo tiempo, el espectador no olvida que está en presencia de un lenguaje cinematográfico. El código se lo recuerda. Es la significación la que habla a través del filme con vocación realista. El analista no busca solo su significado, ya que ello supone la lectura de un código (algo que ya hace en el análisis narratológico o estructural), sino más bien el reconocimiento de lo que ya existe, pero que es intraducible: lo que se ha posado frente a la cámara bajo el paraguas de lo obtuso. Eso que posa, sin embargo, es un acontecimiento para los estándares del dispositivo visual, pues es digno de verse, y por lo tanto digno de filmarse. Así como "fotografiar es apropiarse de lo fotografiado" (Sontag 14), filmar la realidad para que aparezca tal cual es implica, de alguna manera, apropiarse de ella, pero también rechazarla. Lo obtuso convierte la experiencia objetiva en una imagen personal o en un recuerdo testimonial que confina la búsqueda de la fotogenia en el cine. A través de este recurso semiótico, el documental consolida una postura moral frente a hechos que, fuera de la pantalla, carecen de centro. Quizás, siguiendo a Pasolini, este cine culturaliza una naturaleza que durante décadas se ha disfrazado como objetiva e imparcial. Para el realizador italiano, el código de los códigos (la realidad) tiene una cualidad que no es transmisible para otro código derivado, como el cine o la fotografía, pues en este la realidad se presenta como sucesión y finitud, mientras que para el código de los códigos, la realidad es circular e ilimitada.

La principal herencia teórica y cinematográfica de Pier Paolo Pasolini se sustenta en la idea de que la realidad no es natural, sino cultural. El cine nos lo revela, y al hacerlo tomamos conciencia de que no se actúa sobre la realidad sino dentro de ella, como si fuera un continuo sistema de signos en el que formamos parte. El cine documental debiera 
tomar nota de esa postura, pues dejaría clara su intención de explicar el complejo universo discursivo del que asume una nítida opción, pero expresada en un código cinematográfico bajo un régimen de verdad que lo aparta de la ficción. El dispositivo documental se alimenta del artificio de la imagen fímica. El no reconocimiento de la realidad como lengua, lejos de facilitar los objetivos retóricos del género, potencian la histórica y naturalista exigencia estilística que le recuerda que no debe apartarse de los hechos, como si la realidad estuviera esperando afuera, lista para ser registrada, sujeta a un orden, nítida, virgen e inexplorada. Por ello, la tesis pasoliniana, lejos de constituirse en un obstáculo para los estudios cinematográficos, es una oportunidad para ampliar los horizontes epistemológicos del campo disciplinar. El objetivo es, ahora, más ambicioso: descifrar la dominación y las luchas simbólicas de una realidad que se muestra simplificada en la gran pantalla.

Como constata Ángel Quintana, la revisión de la teoría semiótica de Pasolini en Estados Unidos lo ha retornado al centro del debate en los estudios fílmicos de Occidente. Según los trabajos de Giuliana Bruno (Heresies: The Body of Pasolinís Semiotics) y de Maurizio Viano (A Certain Realism. Making Use of Pasolini's Film Theory and Practice), la reflexión de Pasolini coincide mucho más ahora que hace treinta años, ya que el cine convertido en industria- ha cambiado la forma de concebir el mundo y de relacionarnos con él. De paso, es también un impulso para una semiótica discursiva o sociosemiótica, que ha encontrado en el cine la justificación para aprovecharlo como medio de expresión de la discursividad que nos hace humanos. Es decir, es la constatación de que la realidad se ha hecho cine. A nuestro juicio, las bases realistas del cine documental se acercan al falso naturalismo del que habla Pasolini, tras homologar gran parte de los procesos perceptivos que nutren la mente del espectador, inconsciente de las estructuras estéticas que componen la gramática infinita de la cinelengua. La ilusión cinematográfica es equivalente, en este caso, a las acciones naturales que se registran y se organizan en un nuevo código audiovisual, pero que otorgan conciencia de una realidad reproducida en otros códigos previos. Es la metáfora de aquel que por primera vez se ve en el espejo y se da cuenta de que es una imagen siempre y solo en el espejo, no siendo el significante "ser humano", sino significante de él mismo en cuanto realidad transmisible.

La revolucionaria tesis de Pasolini, más que un obstáculo epistemológico, se ha convertido en un impulso para comprender la naturaleza de un género cinematográfico con escaso desarrollo teórico. El principal efecto es la reactualización de los escritos semióticos de Charles Sanders Peirce. Cuando Pasolini da por superada la semejanza icónica de la imagen cinematográfica, le hace un guiño al atributo más emblemático del cine realista: su estatus indicial. La existencia física y natural de un mundo precinematográfico transparenta el signo mismo. La génesis del signo atribuida al referente es lo que hace posible su invisibilización. Con Peirce, no es pertinente definir el cine documental fuera de sus circunstancias, es decir, fuera de su inscripción referencial y su eficacia pragmática. La característica esencial del género debe buscarse no en el resultado sino en su génesis. El resultado es siempre el mismo en el cine, no así su génesis. Es el núcleo de su dispositivo. Se destaca, entonces, la génesis del dispositivo en detrimento del resultado. De insistir 
en lo último, no podríamos diferenciar una película de ficción de un falso documental. Con Peirce, entonces, saltamos el obstáculo de la semejanza. Al igual que la fotografía, el cine documental es indicial. Sin embargo, al cine parece abrumarle el peso de la realidad. El índex cinematográfico debe explicar, interpretar y comentar lo que desnuda. La fotografía, en cambio, es muda. Bruta, para algunos. Ese simple momento que la cámara oscura registra, se convierte en un componente esencial para la experiencia fílmica. Condimentado por la diégesis y la retórica, la realidad en el cine se convierte en ficcional. Dicho aspecto supera la gramaticalidad de la imagen fija, verbalizándola, poniéndola en perspectiva y sumergiéndola en un conflicto dramático.

Al atomizar la realidad, la cámara del documentalista -al igual que la del fotógrafodemocratiza y pone a disposición del espectador formas de participación en la que una experiencia de filmación se convierte en una manera de ver y sentir desde imágenes que se apartan de la mera representación. La certeza de que el cine documental abandonó la búsqueda de la copia para constituirse en un lenguaje con su propio estatuto ontológico es la clave para superar falsos dilemas e interpretaciones erróneas de lo real. La fenomenología propone una nueva relación entre la imagen y la realidad. Al igual que en la caverna de Platón, en el cine de no-ficción no es verdadero aquello que busca el parecido a algo real, sino lo que se constituye por sí mismo en el universo de lo posible, desde la experiencia de lo vivido, a partir de las herramientas generativas que emergen de la conciencia del espectador. En definitiva, hemos planteado una manera de encarar la cuestión del realismo en el cine documental que señala cierto retorno hacia el referente, pero liberado del ilusionismo mimético. Esta referencialización inscribe a la imagen fílmica en el campo de una pragmática irreductible: el filme se vuelve inseparable de su experiencia referencial, del acto que lo funda.

El documental es, ante todo, índex. Luego adquiere rasgos de semejanza y puede ser interpretado como signo. Del mismo modo, el artificio de la representación que se expone en todo filme documental y que lo revela en cuanto tal, anula su efecto como engaño y abre el horizonte como una verdad que se narra y que no requiere veracidad testimonial para manifestarse. Este recurso estético aleja al género de cualquier sospecha de mentira, situación que lo confirma como un dispositivo cuyo régimen de control descansa en el naturalismo que logran sus imágenes en la conciencia del espectador. Se rige principalmente por la dimensión visual del dispositivo. Y como todo artificio, esconde mecanismos culturales e ideológicos, actuando como una autoridad.

\section{Referencias}

Barthes, Roland. Lo obvio y lo obtuso. Barcelona: Paidós, 1986. Medio impreso.

Bruno, Giuliana. "Heresies: The Body of Pasolini's Semiotics”. Cinema Journal 3 (1991): 22-24. Medio impreso.

Català, Josep Maria. La violación de la mirada. La imagen entre el ojo y el espejo. Madrid: Fundesco, 1993. Medio impreso. 
---. La imagen compleja. Barcelona: Servie de Publicacions, UAB, 2005. Medio impreso. Eco, Umberto (1982). Lector in fábula. Barcelona: Lumen, 1982. Medio impreso.

---. La estructura ausente. Barcelona: Randon House Mondadori, 2011. Medio impreso.

Mariniello, Silvestra. Pier Paolo Pasolini. Madrid: Cátedra, 1999. Medio impreso.

Metz, Christian. Ensayos sobre la significación en el cine (1964-1968). Volumen I. Barcelona: Paidós, 2002. Medio impreso.

Pasolini, Pier Paolo. Escritos corsarios. Barcelona: Planeta, 1983. Medio impreso.

---. Empirismo herético. Córdoba: Brujas, 2005. Medio impreso.

Quintana, Ángel. Fábulas de lo visible. El cine como creador de realidades. Barcelona: Acantilado, 2003. Medio impreso.

Schaeffer, Jean-Marie. La imagen precaria del dispositivo fotográfico. Madrid: Cátedra, 1990. Medio impreso.

Sontag, Susan. Sobre la fotografía. Barcelona: Random House Mondadori, 2008. Medio impreso.

Viano, Maurizio. A Certain Realism. Making Use of Pasolinís Film Theory and Practice. Los Angeles, CA:University Press, 1993. Medio impreso.

Recibido: 31 octubre 2012

Aceptado: 13 mayo 2013 